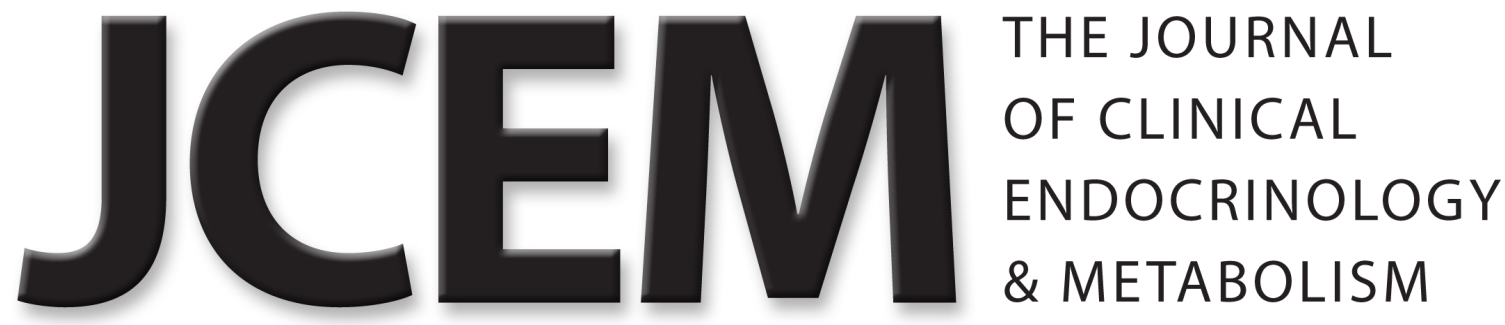

\title{
Cabergoline in the Treatment of Hyperprolactinemia: A Study in 455 Patients
}

Johan Verhelst, Roger Abs, Dominique Maiter, Annick van den Bruel, Mark Vandeweghe, Brigitte Velkeniers, Jean Mockel, Gerard Lamberigts, Patrick Petrossians, Peter Coremans, Charles Mahler, Achille Stevenaert, Jan Verlooy, Christian Raftopoulos and Albert Beckers

J. Clin. Endocrinol. Metab. 1999 84: 2518-2522, doi: 10.1210/jc.84.7.2518

To subscribe to Journal of Clinical Endocrinology \& Metabolism or any of the other journals published by The Endocrine Society please go to: http://jcem.endojournals.org//subscriptions/
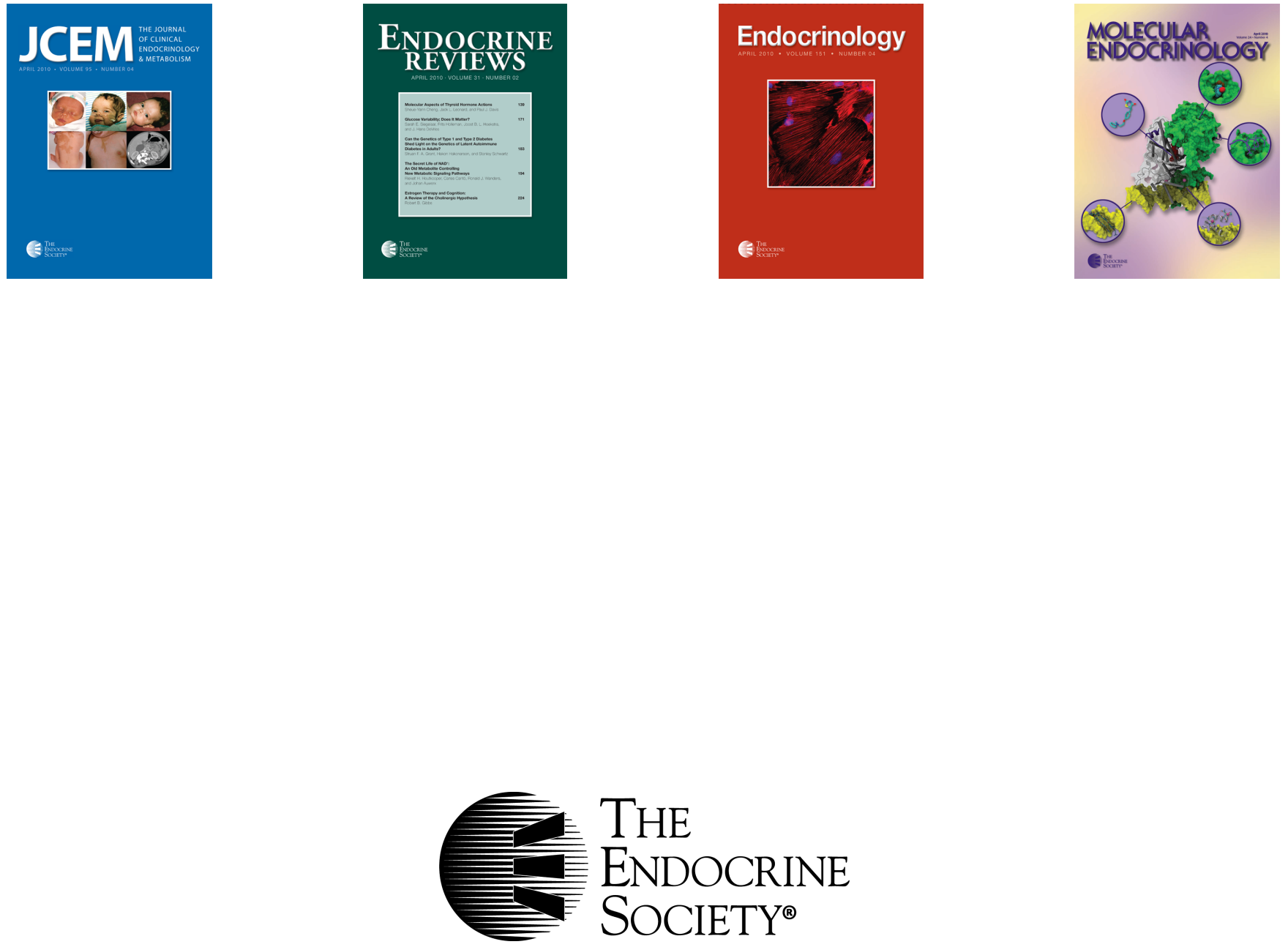


\title{
Cabergoline in the Treatment of Hyperprolactinemia: A Study in 455 Patients
}

\author{
JOHAN VERHELST, ROGER ABS, DOMINIQUE MAITER, \\ ANNICK VAN DEN BRUEL, MARK VANDEWEGHE, BRIGITTE VELKENIERS, \\ JEAN MOCKEL, GERARD LAMBERIGTS, PATRICK PETROSSIANS, \\ PETER COREMANS, CHARLES MAHLER, ACHILLE STEVENAERT, JAN VERLOOY, \\ CHRISTIAN RAFTOPOULOS, AND ALBERT BECKERS
}

Departments of Endocrinology/Neurosurgery, Middelheim Ziekenhuis B-2018 Antwerpen (J.V., C.M.); Universitair Ziekenhuis, B-2650 Antwerpen (R.A., P.C., Ja.V.); Cliniques Universitaires St-Luc, B-1200 Bruxelles (D.M., C.R.); Universitair Ziekenhuis B-3000 Leuven (A.V.), Universitair Ziekenhuis B-9000 Gent (M.V.), Université Libre de Bruxelles (J.M.), B-1070 Bruxelles, Vrije Universiteit, B-1090 Brussel (B.V.), Sint-Jan Ziekenhuis B-8000 Brugge (G.L.), Université de Liège (P.P., A.S., A.B.), B-4006 Liège, Belgium

\begin{abstract}
Cabergoline is a new long-acting dopamine agonist that is very effective and well tolerated in patients with pathological hyperprolactinemia. The aim of this study was to examine, in a very large number of hyperprolactinemic patients, the ability to normalize PRL levels with cabergoline, to determine the effective dose and tolerance, and to assess the effect on clinical symptoms, tumor shrinkage, and visual field abnormalities. We also evaluated the effects of cabergoline in a large subgroup of patients with bromocriptine intolerance or -resistance.

We retrospectively reviewed the files of 455 patients (102 males and 353 females) with pathological hyperprolactinemia treated with cabergoline in 9 Belgian centers. Among these patients, $41 \%$ had a microadenoma; $42 \%$, a macroadenoma; $16 \%$, idiopathic hyperprolactinemia; and $1 \%$, an empty sella. The median pretreatment serum PRL level was $124 \mu \mathrm{g} / \mathrm{L}$ (range, 16-26,250 $\mu \mathrm{g} / \mathrm{L}$ ). A subgroup of 292 patients had previously been treated with bromocriptine, of which 140 showed bromocriptine intolerance and 58 showed bromocriptine resistance.

Treatment with cabergoline normalized serum PRL levels in $86 \%$ of all patients: in $92 \%$ of 244 patients with idiopathic hyperprolactinemia or a microprolactinoma and in $77 \%$ of 181 macroadenomas. Pretreatment visual field abnormalities normalized in $70 \%$ of patients, and tumor shrinkage was seen in $67 \%$ of cases. Side effects were noted
\end{abstract}

in $13 \%$ of patients, but only $3.9 \%$ discontinued therapy because of side effects. The median dose of cabergoline at the start of therapy was 1.0 $\mathrm{mg} /$ week but could be reduced to $0.5 \mathrm{mg} /$ week once control was achieved. Patients with a macroprolactinoma needed a higher median cabergoline dose, compared with those with idiopathic hyperprolactinemia or a microprolactinoma: $1.0 \mathrm{mg} /$ week $v s$. $0.5 \mathrm{mg} / \mathrm{week}$, although a large overlap existed between these groups. Twenty-seven women treated with cabergoline became pregnant, and 25 delivered a healthy child. One patient had an intended abortion and another a miscarriage. In the patients with bromocriptine intolerance, normalization of PRL was reached in $84 \%$ of cases, whereas in the bromocriptine-resistant patients, PRL could be normalized in $70 \%$.

We confirmed, in a large-scale retrospective study, the high efficacy and tolerability of cabergoline in the treatment of pathological hyperprolactinemia, leaving few patients with unacceptable side effects or inadequate clinical response. Patients with idiopathic hyperprolactinemia or a microprolactinoma, on average, needed only half the dose of cabergoline as those with macroprolactinomas and have a higher chance of obtaining PRL normalization. Cabergoline also normalized PRL in the majority of patients with known bromocriptine intolerance or -resistance. Once PRL secretion was adequately controlled, the dose of cabergoline could often be significantly decreased, which further reduced costs of therapy. (J Clin Endocrinol Metab 84: 2518-2522, 1999)
D OPAMINE AGONISTS are the first-line treatment for the majority of patients with hyperprolactinemic disorders (1). Bromocriptine, introduced in 1971, is the original preparation against which newer dopamine agonists are compared. It is effective in suppressing PRL hypersecretion, reducing prolactinoma size, and restoring gonadal function (2). However, a significant proportion of patients (up to $20 \%$ ) does not tolerate the drug at therapeutic doses or is resistant. In addition, because of a short half-life, bromocriptine usually has to be taken twice or three times a day, making it less convenient for long-term therapy. Cabergoline, another ergot derivative, has been developed to overcome these dis-

Received December 28, 1998. Revision received March 12, 1999. Accepted March 22, 1999.

Address all correspondence and requests for reprints to: Johan Verhelst, M.D., Algemeen Ziekenhuis Middelheim, Lindendreef 1, B-2020 Antwerpen, Belgium. E-mail: johan.verhelst@ocmw.antwerpen.be. advantages. With duration of action up to 14 days after a single dose, cabergoline needs to be taken only once or twice weekly (3). In a large comparative double-blind study in female patients with idiopathic hyperprolactinemia or a microprolactinoma, cabergoline was significantly more effective than bromocriptine in suppressing PRL secretion and restoring the menstrual cycle and had a slightly superior tolerability (4). Similarly, better results were obtained with cabergoline, compared with bromocriptine, in macroprolactinomas (5-7). Also, in males, cabergoline restored sexual function and fertility earlier than bromocriptine (8). Finally, a majority of patients intolerant or resistant to bromocriptine responded adequately to cabergoline (9-11). Because the number of clinical studies with cabergoline is still limited, compared with data collected with bromocriptine, we retrospectively analyzed our own experience with cabergoline in a very large cohort of patients with pathological hyperprolactinemia. We examined baseline characteristics predict- 
ing success of treatment and the average maintenance dose of the drug necessary to control PRL levels according to the cause of hyperprolactinemia. We also determined the effects of cabergoline in a large subgroup of patients not responding well to bromocriptine because of resistance or intolerance.

\section{Subjects and Methods}

\section{Subjects}

Cabergoline [Dostinex (Sostilar in Belgium), Pharmacia \& Upjohn, Inc., Brussels, Belgium] has been available for compassionate use in hyperprolactinemic patients in Belgium since 1989. Whereas, initially, only patients resistant or intolerant to bromocriptine were treated with cabergoline, the drug became recently available for all patients with pathological hyperprolactinemia. We retrospectively reviewed the files of 455 patients [102 (22\%) males and $353(78 \%)$ females] with pathological hyperprolactinemia, treated (on a compassionate-need basis) with cabergoline, in 9 Belgian centers. Based on the amount of medication provided by the manufacturer, this cohort was estimated to be close to $90 \%$ of all patients treated with cabergoline for hyperprolactinemia in Belgium. The median basal PRL serum level was $124 \mu \mathrm{g} / \mathrm{L}$; range, $16-26250 \mu \mathrm{g} / \mathrm{L}$. Secondary hyperprolactinemia, caused by medication, and hypothyroidism or pituitary stalk compression were excluded (the latter based upon radiological imaging, pathological examination (in case of surgery), or a PRL cutoff value of $200 \mathrm{ng} / \mathrm{mL}$ ). At diagnosis, 174 $(41 \%)$ of patients had a microadenoma; $181(42 \%)$, a macroadenoma; 70 $(16 \%)$, an idiopathic hyperprolactinemia; and $5(1 \%)$, an empty sella. Data on tumor volume was missing or inaccessible in 25 patients $(6 \%)$. A total of $116(25 \%)$ patients had surgery, and $14(3.1 \%)$ had radiotherapy, before starting cabergoline, after a median delay of 42 months (range, 1-204 months) and 32 months (range, 7-121 months), respectively. Of all patients, $34(8.7 \%)$ had associated ACTH deficiency, 35 $(8.4 \%)$ had TSH deficiency, 57 (15\%) had GH deficiency, and $1(0.3 \%)$ had diabetes insipidus. Sixty-four patients $(14 \%)$ had visual field defects; 71 $(16 \%)$ had symptoms of migraine. Of the 292 patients previously treated with bromocriptine, 198 were changed to cabergoline because of resistance (58 patients) or intolerance (140 patients) to bromocriptine, 16 because of a combination of resistance and intolerance, and 78 for various other reasons (usually convenience or better compliance). Details of the patient characteristics are given in Table 1.

\section{Study design}

Cabergoline was usually started at a dose of $0.25 \mathrm{mg}$ or $0.5 \mathrm{mg}$ twice weekly. A dose adaptation was made every 2 or 3 months, until stabilization, after which the patients were usually seen every $4-6$ months. Once a pronounced and stable suppression of the PRL levels was ob-

TABLE 1. Baseline characteristics of 455 hyperprolactinemic patients treated with cabergoline

\begin{tabular}{lcc}
\hline \multicolumn{1}{c}{ Characteristic } & $\begin{array}{c}\text { All } \\
\mathrm{n}=455\end{array}$ & $\begin{array}{c}\text { Previously treated } \\
\text { with bromocriptine } \\
\mathrm{n}=292\end{array}$ \\
\hline Gender $_{\mathrm{Age}^{a}}$ (yr) & $102 \mathrm{M} / 353 \mathrm{~F}$ & $60 \mathrm{M} / 232 \mathrm{~F}$ \\
Visual field defect $_{\text {Baseline serum prolactin }}{ }^{b}$ & $35.9 \pm 13.5$ & $34.2 \pm 12.3$ \\
$\quad(\mu \mathrm{g} / \mathrm{L})$ & 64 & 42 \\
Surgery & $124(16-26250)$ & $145(16-12440)$ \\
Radiotherapy & 116 & 92 \\
Idiopathic hyperprolactinemia & 14 & 12 \\
Microadenoma & 70 & 43 \\
Macroadenoma & 174 & 116 \\
Empty sella & 181 & 110 \\
Other $^{c}$ & 5 & 3 \\
\hline
\end{tabular}

M, Male; F, female.

${ }^{a}$ Values are means $\pm \mathrm{SD}$.

${ }^{b}$ Results are expressed by the median, with the first and third quartiles between parenthesis.

${ }^{c}$ Unknown etiology or unknown size. tained, the dose of cabergoline was often reduced. Whenever pregnancy occurred or was planned, cabergoline was discontinued until after delivery. From the files, the following data were retrieved: basal symptoms, initial PRL level, basal tumor volume with dimensions, category of tumor volume (micro- and macroadenoma, empty sella), additional pituitary deficiencies, previous treatments (surgery, radiotherapy), and additional pathology. Data retrieved during cabergoline treatment were: reason for starting therapy, date of start of treatment, pretreatment PRL level, nadir PRL level, clinical effects, drug dose after reaching nadir PRL, drug dose at the time of evaluation, evolution of tumor volume (with dimensions and estimated shrinkage), duration of therapy, reported side effects, reason of discontinuing therapy, pregnancy, and fetal outcome. Tumor volume was evaluated by computed tomography scanning $(8 \%)$ or magnetic resonance imaging examination (92\%). Evolution of tumor size was estimated by the radiologist in each center, by comparing directly the initial with the latest radiographic documents. Patients were treated with cabergoline for a median of 28 months (range, 1-99 months). In the subgroup of patients previously treated with bromocriptine, 99 were changed to cabergoline without a prolonged washout period. In these patients, changes of PRL levels or symptoms were evaluated, compared with baseline values.

\section{Hormone assays}

Serum PRL and other hormones were measured with commercially available kits (immunoradiometric, immunoenzymatic, or RIA. The upper range of normal, for serum PRL concentration, was considered less than $10 \mu \mathrm{g} / \mathrm{L}$ in males and less than $20 \mu \mathrm{g} / \mathrm{L}$ in females. The converting factor for PRL was: $33.6 \mathrm{mU} / \mathrm{L}=1 \mu \mathrm{g} / \mathrm{L}$.

\section{Statistics}

Because data on PRL levels and dose of medication did not follow a normal distribution, all results are expressed in median levels, with the total range or first (Q1) and third (Q3) quartiles. If the number of patients with certain clinical effects or side effects is given, both the absolute number and percentage of all patients are reported. Statistical differences were calculated with nonparametrical tests, and the limit of significance was considered as $P<0.05$.

\section{Clinical response}

\section{Results}

Normalization of the menstrual cycle was obtained in 227 of $254(89 \%)$ females in whom it was assessable. Twentyseven of these patients became pregnant under therapy with cabergoline, and 25 delivered a healthy child. One patient had a miscarriage, and the other had a deliberate abortion. Excluded from this analysis were 99 female patients, either menopausal (47 patients), having undergone hysterectomy, on estrogen therapy, or with insufficient clinical data. Normalization of libido and potency was noted in 46 (81\%) of 57 males in whom it could be evaluated. Excluded were males with normal libido at baseline (19 patients) or with insufficient clinical data (26 patients). Normalization of visual fields was demonstrated in 33 of 47 (70\%) patients. In 7 of $14(50 \%)$ patients without visual field improvement, this was considered to be the result of absent tumor shrinkage; in 4, the result of insufficient shrinkage $(<25 \%)$; and in 3, the result of irreversible damage to the chiasm. Symptoms of migraine significantly improved in 51 of 71 patients (72\%).

\section{PRL secretion}

Normalization of PRL levels was achieved in 379 of 440 $(86 \%)$ patients and a PRL decrease of at least $75 \%$ was obtained in 34 (56\%) of the remaining 61 patients. Data from 15 patients were not available for analysis of biochemical effi- 
cacy because of premature stop of therapy because of side effects (4 patients), pregnancy (2 patients), or noncompliance (9 patients). The median serum PRL nadir attained was 5.6 $\mu \mathrm{g} / \mathrm{L}$ (Q1-Q3: 2.0-11.4 $\mu \mathrm{g} / \mathrm{L}$; range, 1.0-1250 $\mu \mathrm{g} / \mathrm{L}$ ), indicating that most patients were well controlled. The time span between the start of therapy and the PRL nadir was 8 months (Q1-Q3: 3-20 months). In addition to the time required for therapeutic effect of the drug, this interval also depended on follow-up visit time interval, patient compliance, and drug tolerance. No patient escaped therapy once control was achieved.

\section{Pituitary tumor size}

The effect of cabergoline on tumor volume could be evaluated in 190 patients. Reasons for exclusion were idiopathic hyperprolactinemia (70 patients), empty sella (5 patients), absence of initial computed tomography scanning or magnetic resonance imaging examination ( 25 patients), microadenomas of too-small volume for meaningful evaluation of shrinkage, or absent control iconography. A more-than-50\% decrease of tumor volume was seen in 58 (31\%) patients, between 25 and 50\% in $30(16 \%)$ patients, and less than $25 \%$ in another $39(21 \%)$. Altogether, a total of $67 \%$ of patients showed some degree of tumor shrinkage.

\section{Cabergoline dose}

In accordance with the standard dose recommended by the manufacturer, the median starting dose of cabergoline was $1.0 \mathrm{mg} /$ week in two gifts (Q1-Q3: 0.5-1.5 mg/week). In 103 patients $(25 \%)$, the maintenance dose of cabergoline could be reduced without deterioration of PRL control, so that the median cabergoline dose was $0.5 \mathrm{mg} /$ week (Q1-Q3: $0.25-1.0 \mathrm{mg} /$ week) at the end of the evaluation period. The scheme of dose for patients is shown in Table 2. In the cabergoline-resistant patients, the dose of cabergoline was increased to a median of $3.5 \mathrm{mg} /$ week (range, 1.5-7.0 mg/week).

\section{Tolerance}

Of all 455 patients, $38(8.5 \%)$ reported minor dopamine agonist-related side effects; and 18 (4\%), major or persisting symptoms. Most prominent complaints were headache (16 patients), postural hypotension (10 patients), nausea (8 patients), and sleepiness (6 patients). Fourteen (3.9\%) patients stopped therapy because of intolerance of cabergoline. Of these, 12 had been intolerant to bromocriptine, as well.

\section{Subgroup analysis}

Micro- vs. macroprolactinomas. In patients with a microprolactinoma, the probability of reaching normal PRL levels was significantly higher than in patients with a macroprolacti- noma [respectively, $93 \%$ vs. $77 \%(P<0.001)$ ], whereas no difference was found between microprolactinoma and idiopathic hyperprolactinemia (93\% vs. $91 \%$, mean of both groups $92 \%$ ). Patients with a microprolactinoma needed significantly lower doses of cabergoline, compared with patients with a macroprolactinoma (median, $0.5 \mathrm{mg} /$ week; Q1Q3: 0.25-1.0 mg/week vs. $1.0 \mathrm{mg} /$ week; Q1-Q3: 0.5-1.5 mg/ week, $P=0.003$ ), although an overlap existed between the two groups.

Male vs. female patients. Male patients had less likelihood of achieving normal PRL levels than females: $75 \%$ vs. $90 \%(P=$ $0.001)$. However, considering the fact that the large majority of males had a macroprolactinoma $(86 \%$ vs. $38 \%$ only for females), gender had no independent influence on success rates. When only microprolactinomas were considered, the outcome was similar in males and females: $92 \%$ vs. $93 \%$.

Basal PRL levels. A weak (but significant) correlation was found between the basal PRL level and the nadir PRL level ( $\mathrm{r}=0.246, P<0.001)$. If patients with idiopathic hyperprolactinemia or those with a microprolactinoma are considered separately, a closer correlation was found between basal PRL value and nadir value (respectively, $\mathrm{r}=0.71$ and $\mathrm{r}=0.79, P<$ $0.001)$, whereas the correlation in macroprolactinomas was similar, as for the whole group $(\mathrm{r}=0.231, P=0.002)$. Also, a loose correlation was found between the basal PRL level and the final dose of cabergoline $(\mathrm{r}=0.162, P=0.001)$.

Bromocriptine resistance. $70 \%$ of the 58 patients in whom bromocriptine failed to normalize PRL were controlled with cabergoline (16 patients with both intolerance and resistance not included in this analysis). They were less likely to achieve normal PRL levels with cabergoline than other patients were (70\% vs. 88\%, $P<0.001$ ) and needed higher doses of cabergoline: median $1.5 \mathrm{mg} /$ week (Q1-Q3: 0.5-3.0 mg/week) vs. $0.5 \mathrm{mg} /$ week (Q1-Q3: 0.25-1.0 mg/week) $(P<0.001)$. Seven $(1.5 \%)$ patients, previously found to be resistant to bromocriptine, were also completely resistant to cabergoline $(<50 \%$ decrease in PRL levels).

Bromocriptine intolerance. Twelve of 140 patients (8.6\%) intolerant for bromocriptine showed a similar intolerance for cabergoline. In general, no significant difference was noted for bromocriptine-intolerant patients in obtaining PRL normalization, compared with others $(84 \%$ vs. $87 \%, P=$ not significant). The median dose of cabergoline was $0.5 \mathrm{mg} /$ week (Q1-Q3: $0.25-1.0 \mathrm{mg} /$ week), a result similar to the values observed in bromocriptine-tolerant or naive patients.

Naive vs. bromocriptine pretreated patients. Patients previously treated with bromocriptine obtained slightly worse results than those who were not (82\% PRL normalization vs. $88 \%$ ), despite a similar percentage of macroprolactinomas $(38 \%$ vs.

TABLE 2. Number and distribution of patients, according to primary and final cabergoline dose (mg/week)

\begin{tabular}{|c|c|c|c|c|c|c|c|c|c|}
\hline Dose (mg/week) & 0.125 & 0.25 & 0.5 & 0.75 & 1 & 1.5 & $1.75-3$ & 3.5 & $>4$ \\
\hline \multirow[t]{2}{*}{ Primary dose } & 1 & 47 & 165 & 6 & 135 & 30 & 33 & 22 & 8 \\
\hline & $0.2 \%$ & $10.5 \%$ & $36.7 \%$ & $1.3 \%$ & $30.1 \%$ & $6.7 \%$ & $7.3 \%$ & $4.9 \%$ & $1.8 \%$ \\
\hline \multirow[t]{2}{*}{ Final dose } & 23 & 73 & 108 & 4 & 78 & 28 & 28 & 15 & 7 \\
\hline & $6.3 \%$ & $20.1 \%$ & $29.7 \%$ & $1.1 \%$ & $21.4 \%$ & $7.7 \%$ & $7.7 \%$ & $4.1 \%$ & $1.9 \%$ \\
\hline
\end{tabular}


$41 \%, P=$ not significant). This difference disappeared, however, if the number of bromocriptine-resistant patients was taken into account.

\section{Discussion}

We confirmed, in a large group of patients, the beneficial effects of cabergoline in hyperprolactinemic disorders. The large cohort of patients and the prolonged treatment period allowed for a close estimation of the general efficacy and side effects of cabergoline in daily clinical practice. In addition, the large number of patients made it possible to evaluate cabergoline in different subgroups of patients and to draw conclusions regarding predicted effects of therapy for specific patients. The limitations of the current study are: the retrospective character of the analysis, and a selection bias of bromocriptine-resistant and/or intolerant patients at the beginning of enrollment.

Our percentage of success in attaining normal PRL levels is very close to that reported in the literature (Table 3). We reached a mean percentage of PRL normalization of $86 \%$, which falls within the margins of $81-93 \%$ success of other studies with combined micro- and macroprolactinomas. When data are split into micro- and macroprolactinomas, the similarity is even more striking. With a percentage of success for combined microprolactinomas and idiopathic hyperprolactinemia of $92 \%$, we had results similar to those of Webster et al. (12) and Muratori et al. (13): respectively, 92 and 96\%. Our results and the previous ones are better than the reference double-blind study of Webster et al. (4), where the success rate was only $83 \%$, most likely because no upward dose adaptations were allowed in this study. Comparing the macroprolactinomas, our success rate of $77 \%$ is close to the results of Biller et al. (5), Ferrari et al. (6), and Colao et al. (7), reaching $61 \%, 73 \%$, and $83 \%$ of success, respectively (Table 3).

Apart from initial tumor volume, a lower pretreatment PRL concentration predicted a better chance for obtaining PRL normalization. The worse results in macroadenomas reflect the known difference in biological behavior between micro- and macroprolactinomas (14).

As anticipated, poorer results were found in the subgroup of bromocriptine-resistant patients, when compared with the other patients. Although the exact mechanism to understand dopamine resistance is not entirely clear, the finding of only few dopamine receptor-binding sites in this group of patients offers an attractive explanation (15). In bromocriptine-intolerant patients, on the other hand, a comparable score was reached $(84 \%)$, underlining the fact that intolerance has a different physiopathological mechanism, compared with resistance. Nevertheless, up to $70 \%$ of 58 bromocriptine-resistant patients did benefit from cabergoline therapy. This is similar to the observations of Jones et al. (9), Delgrange et al. (10), and Colao et al. (11), with (respectively) 1,2/3 (67\%), and $15 / 18(79 \%)$ of bromocriptine-resistant patients responding well to therapy with cabergoline. Furthermore, $84 \%$ of patients considered poorly tolerant for bromocriptine were controlled with cabergoline, and only $8.6 \%$ were similarly intolerant for cabergoline. In agreement with this, 4 times more patients treated with bromocriptine, under double-blind conditions, discontinued therapy because of intolerance, as opposed to cabergoline: $12 \%$ vs. $3 \%$ (4). The possibility to offer effective medical therapy in the majority of bromocriptine-resistant and/or intolerant patients or those with low compliance will make additional surgery and/or radiotherapy unnecessary in their situations. Cabergoline, therefore, further extends the place of medical therapy as primary treatment for prolactinomas. Furthermore, if less prolactinoma patients must undergo additional surgery and/or radiotherapy, cabergoline will probably also decrease the incidence of pituitary deficiency syndromes as a result of these procedures in this group of patients.

Up to $69 \%$ of our patients had significant tumor shrinkage, a result falling between limits of all other studies (48-83\%), although differences in what is considered significant shrinkage and differences in selection of patients make exact comparisons hazardous (Table 3$)$.

The number of side effects (13\%) was relatively low, as can be expected from a retrospective study in which only drugrelated symptoms were recorded. It is considerably lower than the figure of $68 \%$ adverse events in the prospective study of Webster et al. (4), where all events were systematically registered. The other studies show figures between these limits: $4-52 \%$ (Table 3). Our data probably underestimate the real number of side effects and reflect what is

TABLE 3. Overview of efficacy and tolerability of cabergoline in patients with hyperprolactinemic disorders

\begin{tabular}{|c|c|c|c|c|c|c|c|c|}
\hline Year & Author & $\begin{array}{c}\text { Micro- }^{\alpha} / \\
\text { macroadenoma }\end{array}$ & $\begin{array}{c}\% \mathrm{PRL} \\
\text { normalization }\end{array}$ & $\begin{array}{l}\% \text { Side } \\
\text { effects }\end{array}$ & $\%$ Dropouts & $\begin{array}{l}\% \text { Tumor } \\
\text { reduction }\end{array}$ & $\begin{array}{c}\text { Bromocriptine- } \\
\text { resistant/intolerant }\end{array}$ & Reference \\
\hline 1989 & Ciccarelli & $27 / 3$ & $81 \%$ & $48 \%$ & $11 \%$ & $71 \%$ & $0 / 7$ & (20) \\
\hline 1989 & Ferrari & $38 / 8$ & $85 \%$ & $15 \%$ & 0 & $83 \%$ & & (21) \\
\hline 1992 & Ferrari & $108 / 19$ & $90 \%$ & $23 \%$ & 0 & $79 \%$ & $10 / 1$ & (22) \\
\hline 1993 & Webster & $161 / 1$ & $92 \%$ & $40 \%$ & $3 \%$ & & $0 / 27$ & (12) \\
\hline 1994 & Webster & $223 / 0$ & $83 \%$ & $68 \%$ & $3 \%$ & & & (4) \\
\hline 1995 & Pascal-V. & $60 / 0$ & $93 \%$ & $52 \%$ & $3.3 \%$ & & & (23) \\
\hline 1996 & Biller & $0 / 15$ & $73 \%$ & Minimal & 0 & $73 \%$ & $5 / 5$ & (5) \\
\hline 1997 & Ferrari & $0 / 65$ & $61 \%$ & $25 \%$ & $4.7 \%$ & $66 \%$ & $16 / 32$ & (6) \\
\hline 1997 & Muratori & $26 / 0$ & $96 \%$ & $24 \%$ & 0 & $68 \%$ & & (13) \\
\hline 1997 & Colao & $8 / 19$ & $85 \%$ & $22 \%$ & 0 & $48 \%$ & $27 / 0$ & (11) \\
\hline \multirow[t]{2}{*}{1997} & Colao & $0 / 23$ & $83 \%$ & $4 \%$ & 0 & $61 \%$ & $6 / 2$ & $(7)$ \\
\hline & Verhelst & $249 / 181$ & $86 \%$ & $13 \%$ & $3.9 \%$ & $67 \%$ & $58 / 140$ & \\
\hline
\end{tabular}

\footnotetext{
${ }^{a}$ Includes idiopathic hyperprolactinemia and empty sella.

${ }^{b}$ Criteria on what is considered significant differs between studies, and the imaging studies are usually only performed on a subgroup of patients.
} 
considered clinically meaningful in daily practice. Few patients $(3.9 \%)$ stopped therapy with cabergoline because of side effects, an observation similar to the results of other studies (3-11\% drop-outs), and our own experience in acromegalic patients treated with high doses of cabergoline $(3.2 \%)(16)$.

The median effective maintenance dose in this study was 0.5 $\mathrm{mg} /$ week, and $56 \%$ of patients could ultimately be controlled with $0.5 \mathrm{mg}$ or lower doses per week. This is a lesser dose than the dose employed in earlier studies, such as the large open study of Webster et al. (12), where only $40 \%$ of patients received $0.5 \mathrm{mg}$ / week or less. It is also half the dose recommended in the product label ( $0.5 \mathrm{mg}$ twice weekly). In the large double-blind study comparing bromocriptine with cabergoline, almost all patients received $1.0 \mathrm{mg}$ / week or more, but no downward dose adjustments were allowed (4). We argue for the fact that lower average doses of cabergoline probably suffice to control PRL levels in many patients and that, once PRL levels are suppressed at the lower limit of normality, it seems wise to drop the dose of cabergoline. A lower average dose will also reduce the cost of this long-term therapy.

The maintenance dose was higher in macroprolactinomas, compared with microprolactinomas (median, $1 \mathrm{mg} /$ week $v$ s. $0.5 \mathrm{mg}$ /week), was loosely dependent on the initial PRL level, and was significantly higher in patients with previously known bromocriptine resistance. In agreement with our results, the study of Colao et al. (11) showed that the median dose of cabergoline, in 24 of 27 bromocriptine-resistant patients, was $1 \mathrm{mg} /$ week or more. Other studies on macroprolactinomas also showed the necessity of a larger dose: in the study of Biller et al. (5), the median dose of cabergoline was $1.0 \mathrm{mg} /$ week, and only 4 of 15 patients needed only $0.5 \mathrm{mg} /$ week.

The experience with bromocriptine during pregnancy is far more extensive than with cabergoline, so that, for women requiring treatment for fertility, bromocriptine is still considered the treatment of choice in most centers. However, recent data showed no detrimental effects of cabergoline on fetal outcome (17-19). In this study, we report 25 uneventful deliveries for patients treated with cabergoline at the time of conception. No increased incidence of malformations was found in the children. Whereas heretofore cabergoline was substituted for bromocriptine in preparation for pregnancy, this might be unnecessary in the future if further data can confirm these encouraging findings.

In conclusion, we confirmed, in a large-scale retrospective study, the high efficacy and tolerability of cabergoline in the treatment of pathological hyperprolactinemia, leaving few patients with unacceptable side effects or inadequate clinical response. Patients with idiopathic hyperprolactinemia or a microprolactinoma, on average, needed only half the dose of cabergoline as macroprolactinomas; and they had a higher chance of obtaining PRL normalization. Cabergoline also normalized PRL in the majority of patients with known bromocriptine intolerance or resistance. This outcome should certainly be taken into account in cost-benefit studies. Once PRL secretion was adequately controlled, the starting dose of cabergoline could often be significantly decreased, which will further reduce costs.

\section{Acknowledgments}

We would like to thank Dr. Willy Stekke (Pharmacia \& Upjohn, Inc., Belgium) for his help in retrieving all the data from the different centers, Prof. Leonard Kaufman (Department of Statistics, Free University Brussels, Belgium) for the statistical analysis, and Pharmacia \& Upjohn, Inc., Belgium, for the generous delivery of cabergoline.

\section{References}

1. Crosignani PG, Ferrari C. 1990 Dopaminergic treatments for hyperprolactinaemic disorders. Baillieres Clin Obstet Gynaecol. 4:441-455.

2. Bevan JS, Webster J, Burke CW, Scanlon MF. 1992 Dopamine agonists and pituitary tumor shrinkage. Endocr Rev. 13:220-240.

3. Ferrari C, Barbieri C, Caldara R, et al. 1986 Long-lasting prolactin-lowering effect of cabergoline, a new dopamine agonist, in hyperprolactinemic patients. J Clin Endocrinol Metab. 63:941-945.

4. Webster J, Piscitelli G, Polli A, Ferrari CI, Ismail I, Scanlon MF. 1994 For the cabergoline comparative study group. A comparison of cabergoline and bromocriptine in the treatment of hyperprolactinemic amenorrhea. N Engl J Med. 331:904-909.

5. Biller BMK, Molitch ME, Vance ML, et al. 1996 Treatment of prolactinsecreting macroadenomas with the once-weekly dopamine agonist cabergoline. J Clin Endocrinol Metab. 81:2338-2343.

6. Ferrari CI, Abs R, Bevan JS, et al. 1997 Treatment of macroprolactinoma with cabergoline: a study of 85 patients. Clin Endocrinol (Oxf). 46:409-413.

7. Colao A, Di Sarno A, Landi ML, et al. 1997 Long-term and low-dose treatment with cabergoline induces macroprolactinoma shrinkage. J Clin Endocrino Metab. 82:3574-3579.

8. De Rosa M, Colao A, Di Sarno A, et al. 1998 Cabergoline treatment rapidly improves gonadal function in hyperprolactinemic males: a comparison with bromocriptine. Eur J Endocrinol. 138:286-293.

9. Jones TH, Fraser RB. 1994 Cabergoline-treated hyperprolactinemia results in pregnancy in a bromocriptine-intolerant patient after seventeen years of infertility. Br J Obstet Gynaecol. 101:349-350.

10. Delgrange E, Maiter D, Donckier J. 1996 Effects of the dopamine agonist cabergoline in patients with prolactinoma intolerant or resistant to bromocriptine. Eur J Endocrinol. 134:454-456.

11. Colao A, Di Sarno A, Sarnacchiaro F, et al. 1997 Prolactinomas resistant to standard dopamine agonists respond to chronic cabergoline treatment. J Clin Endocrinol Metab. 82:876-883.

12. Webster J, Piscitelli G, Polli A, et al. 1993 The efficacy and tolerability of long-term cabergoline therapy in hyperprolactinaemic disorders: an open, uncontrolled, multicentre study. Clin Endocrinol (Oxf). 39:323-329.

13. Muratori M, Arosio M, Gambino G, Romano C, Biella O, Faglia G. 1997 Use of cabergoline in the long-term treatment of hyperprolactinemic and acromegalic patients. J Endocrinol Invest. 20:537-546.

14. Delgrange E, Trouillas J, Maiter D, Donckier J, Tourniaire J. 1997 Sex-related difference in the growth of prolactinomas: a clinical and proliferation marker study. J Clin Endocrinol Metab. 82:2102-2107.

15. Pelligrini I, Rasolonjanahary R, Gunz G, et al. 1989 Resistance to bromocriptine in prolactinomas. J Clin Endocrinol Metab. 69:500-509.

16. Abs R, Verhelst J, Maiter D, et al. 1998 Cabergoline in the treatment of acromegaly: a study in 64 patients. J Clin Endocrinol Metab. 83:374-378.

17. Ciccarelli E, Grottoli S, Razzore P, et al. 1997 Long-term treatment with cabergoline, a new long-lasting ergoline derivative, in idiopathic or tumourous hyperprolactinemia and outcome of drug-induced pregnancy. J Endocrinol Invest. 20:547-551.

18. Robert E, Musatti L, Piscitelli G, Ferrari CI. 1996 Pregnancy outcome after treatment with the ergot derivative, cabergoline. Reprod Toxicol. 10:333-337.

19. Rains CP, Bryson HM, Fitton A. 1995 Cabergoline. A review of its pharmacologic properties and therapeutic potential in the treatment of hyperprolactinaemia and inhibition of lactation. Drugs. 49:255-279.

20. Ciccarelli E, Giusti M, Miola C, et al. 1989 Effectiveness and tolerability of long-term treatment with cabergoline, a new long-lasting ergoline derivative, in hyperprolactinemic patients. J Clin Endocrinol Metab. 69:725-728.

21. Ferrari C, Mattei A, Melis GB, et al. 1989 Cabergoline: long-acting oral treatment of hyperprolactinemic disorders. J Clin Endocrinol Metab. 68:1201-1206.

22. Ferrari C, Paracchi A, Mattei AM, de Vincentiis S, D'Alberton A, Crosignani P. 1992 Cabergoline in the long-term therapy of hyperprolactinemic disorders. Acta Endocrinol (Copenh). 126:489-494.

23. Pascal-Vigneron V, Weryha G, Bosc M, Leclere J. 1995 Hyperprolactinemic amenorrhea: treatment with cabergoline $v s$. bromocriptine. Results of a national multicenter randomized double-blind study. Presse Med. 24:753-757. 